\title{
Entry-level survival in a post-crisis world
}

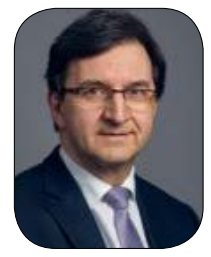

Constantinus Politis

MD, DDS, MM, MHA, PhD

Professor \& Chairperson

Editor-in-Chief

Dear readers,

Every major crisis is an opportunity to either perish or be successful. Not in the least for medical and dental journals. Journals see their advertising revenues plummeting. At the same time digitization offers relief. Zoom meetings replace physical meetings and are an excellent opportunity for a journal editorial board to have regular meetings despite their international membership. Now that even top-journals have accepted to pre-publish manuscripts before peer-review and to allow all peers publicly scrutinize the submission an irreversible new way of peer-reviewing has entered the scene: crowd-reviewing by peers. This has led to the withdrawal of many manuscripts. The international community of scientists is in need of open access papers of high quality since subscription fees for most universities and individual medical doctors and dentists are no longer affordable. Leaving printed issues in favor of open access electronic journals would benefit all readers.

A worrying trend is the surge in number of predator journals accepting any submission in return for a submission fee. Seducing journal names hide their real intent. The ones suffering are not top journals or top scientists but entry level journals and beginning scholars and researchers. There is a definite need for journals accepting work of junior members of a staff. Writing is a skill and as any skill positive feedback is needed to motivate young people to aspire to a next level.

As the name says the Stomatology Edu Journal (Stoma Edu J) has the ambition to Educate. Education is not for the readership only, but also for those submitting. The advantage of an entry level journal is that no 'big data' are needed, that no complicated statistics are required to accept a submission. Reviewers are well aware of the standards that need to be fulfilled to present a paper to the peers. As soon as a paper with a decent content has been submitted and accepted, its open access publication will motivate juniors to pursue an academic career and to produce submissions for a next level journal.

Globalization of economic progress has increased competition among universities and the increase of manuscripts has led to major rejection figures in many journals. This rises the standards that can be achieved, but at the same time the Europe suffers from lack of funding for medical and dental research at University level. The presence and survival of continental journals is worthwhile to serve the European academic world. This journal therefore needs to do whatever is needed to meet the requirements set for entering InCites Journal Citation Reports of Clarivate Analytics. A good way to start are zoom-meetings to discuss concerns of any kind and promote initiatives which progressively enhance the level of submissions.

Sincerely yours,

C. Politis

Editor-in-Chief 